\title{
Ver o no ver (la ecografia): nuevos desafíos para el pediatra de Atención Primaria
}

\author{
I. Osiniri Kippes, en nombre del Grupo de trabajo \\ de Ecografía Clínica Pediátrica de la AEPap
}

Publicado en Internet:

23-diciembre-2014

Inés Osiniri Kippes: ines@sldig.com
Servicio de Pediatría del Hospital de Figueres y CAP La Escala. Figueres. Gerona. España.
En los últimos tiempos, el rol del pediatra de Atención Primaria (PAP) es cada vez más importante; la realidad es que hoy es una figura que incorpora las características de médico polivalente, de primera línea y con alta capacidad resolutiva, como así lo demandan las familias y los servicios públicos de salud.

El avance de las nuevas tecnologías, que van creciendo y transformándose día a día, y el fácil acceso a ellas, tanto para los profesionales como para los pacientes, exigen del pediatra que esté constantemente dispuesto y permeable para mantenerse informado. Ocurre con frecuencia que el exceso de oferta informativa supera nuestra capacidad (tiempo, costes e interés). De la preocupación por los efectos del torrente informativo sobre la capacidad del PAP para dar respuesta a las necesidades de los pacientes surge la necesidad de innovar y aprender nuevas habilidades, el manejo de nuevas tecnologías, constituyendo en su conjunto un monumental reto para el pediatra del siglo XXI.

La ecografía clínica, en la medicina primaria de adultos (Urgencias hospitalarias y prehospitalarias, Atención Primaria), es un campo aún poco desarrollado pese a que ya desde hace muchos años se dedican esfuerzos notables de profesionales y sociedades científicas. La situación en Pediatría es diferente, la ecografía clínica es, en casi todos los entornos asistenciales, una herramienta desconocida por el pediatra general. Probablemente esto responda a la ausencia de la formación específica en este campo durante los estudios pregrado y en el MIR, donde tradicionalmente el diagnóstico por imágenes se concentran en los servicios de radiología de los hospitales.

La ecografía en Pediatría puede ser el segundo fonendo, ese instrumento que siempre nos acompaña, ya que aporta información necesaria para comprender la fisiopatología y facilitar la toma de decisiones "más acertadas" en un mismo momento. La ecografía multiplica su valor cuando es realizada por el propio clínico y en el momento y lugar donde se desarrolla el encuentro clínico. Por otra parte, la ecografía pediátrica tiene una gran ventaja sobre la ecografía en adultos, y es que el niño es una "gran ventana acústica” debido al escaso panículo adiposo y la mayor proporción de agua corporal.

La principal desventaja es que es una técnica dependiente del operador, es decir, se requiere una formación adecuada (extensa y de calidad) antes de ver los resultados y poder disfrutar de sus resultados en la consulta.

Sin duda, la ecografía clínica ha de incorporarse al currículo formativo y al conjunto de habilidades cotidianas propias de los PAP. 
El pediatra necesita conocer las indicaciones y las limitaciones de los ultrasonidos y recibir una formación de calidad, tutorizada y acreditada.

La ecografía es el primer método de imagen para el estudio de la patología abdominal del niño. Las indicaciones más usuales de la ecografía pediátrica en AP son:

- Lactantes con ectasia piélica de diagnóstico prenatal.

- Niño febril con sospecha de infección urinaria.

- Niño con dolor abdominal y exploración física normal.

- Lactante irritable con sospecha de reflujo gastroesofágico.

- Lactante con vómitos y sospecha de estenosis hipertrófica de píloro.

- Niña con aumento de la velocidad de crecimiento y sospecha de pubertad precoz.

- Lactante con aumento del tamaño escrotal, para visualizar hidrocele.

- Lactante con bolsas escrotales vacías, para documentar la criptorquidia y los testículos en ascensor.

- Niño con dolor testicular y signos inflamatorios locales.
- Niño con sospecha de neumonía.

- Lactante con ictericia prolongada.

- Hepatomegalia o esplenomegalia.

- Adenopatías palpables.

- Parotiditis.

- Adenitis o absceso superficial.

- Niño con cojera.

Muchos centros de Atención Primaria cuentan ya con ecógrafos que son utilizados básicamente por los médicos de familia. Cada vez más pediatras muestran su interés en el manejo de esta técnica y buscan y reciben formación en ecografía pediátrica. Esto ha llevado a que diversas sociedades científicas, como la Asocación Española de Pediatría de Atención Primaria (AEPap), se interesen y promuevan la formación del PAP en ecografía.

Los profesionales y las sociedades científicas, la sociedad y las instancias responsables de la planificación y desarrollo de la formación y de los servicios regionales de salud deberán ponerse a ello, y a este objetivo se dedica este escrito con el que saludamos la iniciativa del recientemente constituido Grupo de trabajo de Ecografía Clínica Pediátrica de la AEPap (www.aepap.org/grupos/grupo-de-eco grafia-clinica-pediatrica/componentes). 